\title{
A Novel Protein Elicitor PeBL2, from Brevibacillus laterosporus A60, Induces Systemic Resistance against Botrytis cinerea in Tobacco Plant
}

\author{
Ghulam Hussain Jatoi (iD ${ }^{1,2 *}$, Guo Lihua ${ }^{1}$, Yang Xiufen ${ }^{1}$, Muswar Ali Gadhi ${ }^{1}$, Azhar Uddin Keerio ${ }^{1}$, \\ Yusuf Ali Abdulle', and Dewen Qiu ${ }^{1 *}$ \\ ${ }^{1}$ State Key Laboratory of Plant Diseases and Insect Pests, Institute of Plant Protection, Chinese Academy of Agricultural \\ Sciences, No. 12 Zhongguancun South Street, Beijing 100081, China \\ ${ }^{2}$ Department of Plant Pathology Sindh Agriculture University Tandojam, Sindh, Pakistan
}

(Received on December 8, 2018; Revised on February 26, 2019; Accepted on March 28, 2019)

Here, we reported a novel secreted protein elicitor PeBL2 from Brevibacillus laterosporus A60, which can induce hypersensitive response in tobacco (Nicotiana benthamiana). The ion-exchange chromatography, high-performance liquid chromatography (HPLC) and mass spectrometry were performed for identification of protein elicitor. The 471 bp PeBL2 gene produces a 17.22 kDa protein with 156 amino acids containing an 84-residue signal peptide. Consistent with endogenous protein, the recombinant protein expressed in Escherichia coli induced the typical hypersensitive response (HR) and necrosis in tobacco leaves. Additionally, PeBL2 also triggered early defensive response of generation of reactive oxygen species $\left(\mathrm{H}_{2} \mathrm{O}_{2}\right.$ and $\left.\mathrm{O}_{2}^{-}\right)$and systemic resistance against of $B$. cinerea. Our findings shed new light on a novel strategy for biocontrol using $B$. laterosporus A60.

Keywords : Botrytis cinereal, Brevibacillus laterosporus A60, novel protein, PeBL2, protein elicitor activity

\footnotetext{
*Co-Corresponding authors

Dewen Qiu

Phone) 0086-13520642805

E-mail) qiudewen@caas.cn

Ghulam Hussain Jatoi

Phone) 00923453854538

E-mail) jatoighulamhussain@hotmail.com

ORCID

https://orcid.org/0000-0002-7266-1567

(c) This is an Open Access article distributed under the terms of the Creative Commons Attribution Non-Commercial License (http:// creativecommons.org/licenses/by-nc/4.0) which permits unrestricted noncommercial use, distribution, and reproduction in any medium, provided the original work is properly cited.
}

Articles can be freely viewed online at www.ppjonline.org.
Handling Editor : Sang, Mee Kyung

Plants live with diverse beneficial microbes in nature, along with complicated environmental surroundings. plants have innate defence mechanisms to resist different harmful pathogens (Cct et al., 2018; Corn et al., 2009; Díeznavajas et al., 2008). Probiotics are very useful in indirectly triggering plant defence responses, which can induce the plant resistant to broad spectrum pathogens (Haas and Défago, 2005; Smolińska and Kowalska, 2018; Ueki et al., 2018). When plant roots are treated with beneficial bacteria, the whole plant becomes resistant, including parts that are above ground, demonstrating the systemic resistance capacity of plants. A broad range of pathogens, including numerous organisms like viruses, bacteria, nematodes, insects, fungi etc., can be resisted by non-pathogens through a process called induced systemic resistance (ISR) (Jain et al., 2013; Ryu et al., 2005; Wu et al., 2018). Apparently the systemic acquired resistance is almost identical to ISR characterized by the motivation through an incompatible pathogen (Kukawka et al., 2018). An extensively studied demonstrated that plant growth-promoting rhizobacteria (PGPR) consists a useful association with the plant root and the rhizosphere (Kloeppe et al., 1999; Ma et al., 2018). Numerous plant species including beans, tomatoes, cucumbers, radishes and Arabidopsis thaliana, can display ISR (Corn et al., 2009; Riera et al., 2018). ISR can triggered by three specific steps: recognition of the elicitor, the signal transduction occurs and the defense related gene expression. Signal transduction mechanisms of ISR remain poorly understood. It has been confirmed that salicylic acid pathway (SA), ethylene pathway (ET) and the jasmonic 
acid (JA) are different regulatory pathways, and act as core candidates in the signaling system, as well as in the defense response (Lai et al., 2018; Pieterse and van Loon, 1999; Zhang et al., 2018a). SA is considered to be the most prominent signaling molecule having a key role in system resistance as well as local defense reactions (Glazebrook, 2001). Several genes, viz. $P R-5, P R-1 a$ and $P R-1 b$, are related to pathogenesis and can be utilized as markers for SA-dependent defenses. The above mentioned JA and ET are also involved in defense response and signaling in plants and play important roles in ISR-mediated signaling pathways (Riera et al., 2018; van Loon et al., 1998). The SA-dependent pathway activation is related to ISR-inducing biocontrol bacteria (Shilina et al., 2018). Pseudomonas fluorescens CHAO induced ISR and lead to PR protein accumulation in tobacco plant, indicating the ISR is associated with SA pathway. Much evidence have suggested that ISR and SAR have similar mechanism, which providing an avenue for the extensive studies related to ISR-mediated defense response in future (Hazotte et al., 2018).

The systemic resistance depends on the enhancement of its defensive signals. All signals that are recognized by plant cells and trigger defense responses are considered as elicitors. Different types of organisms in nature, including fungi, bacteria, oomycetes and viruses, can produce elicitors, including different chemical viz. proteins, lipids, glycoproteins, oligosaccharides and peptides (Ellis et al., 2009; Islam et al., 2018; Nürnberger, 1999). Gram positive plant-pathogenic bacteria produce one type of protein elicitor called a hairpin, which is a multifunctional protein (Wang et al., 2015; Wei et al., 1992). More recently, various fungal elicitors, including MoHrip1 from Magnaporthe oryzae, PevD1 from Verticillium dahlia, and Hrip1 from Alternaria tenuissima, respectively, have been shown to activate the defence responses of plants (Kulye et al., 2012; Zhang et al., 2018b). Some studies showed that elicitors can also be isolated from probiotics. For example, an ISR-eliciting Bacillus cereus strain produces dimethyl disulphide (DMDS), which plays a key role in ISR to $B$. cereus $\mathrm{C} 1 \mathrm{~L}$ and suppress plant fungal diseases (Huang et al., 2012). Additionally, Pseudomonas fluorescens SS101 produces massetolide A, which shows defensive capacity against Phytophthora infestans in tomato by eliciting ISR (Cui et al., 2018). Bacillus subtilis S499 produces fengycins and surfactants, which have ISR-eliciting defensive capacity (Ongena et al., 2007).

ROS are involved in the hypersensitive response (HR) as well as elicitor signal transduction system (Allen et al., 2004; Hu et al., 2018; Jones and Dangl, 2006). ROS have been associated with the accumulation of plant secondary metabolites and are ultimately required for enhancing plant immunity reactions (Asai et al., 2008; Somasundaram et al., 2018; Zhao et al., 2005). The second stage in the activation concerning defence response occurs within few hours of elicitor ingestion. This stage includes the activation of defence-associated genes related to cytoderm reinforcement. This term codes for the mechanism involved in the accumulation of synthesized phytoalexins on PR proteins and ranking for the induction defense compounds, which include phenylalanine ammonia lyase (PAL), or callose, and phenolic compounds, (Blumwald et al., 1998; Wei et al., 2018).

B. laterosporus can minimize infections by enhancing immunity in plants (Akköprü and Demir, 2005; Chandel et al., 2010). Previously, a protein elicitor PeBL1, having molecular weight of $12.833 \mathrm{kDa}$, has been identified from B. laterosporus strain A60 (Wang et al., 2015; Zhao et al., 2012). But, there are no detailed evidences for strain A60 activating systemic resistance. In this study, we isolated a protein elicitor PeBL2 from $B$. laterosporus, which can induce systemic immunity against $B$. cinerea in tobacco plants. PeBL2 can activate systemic resistances as well as an early plant defense-response. The results will definitely help out for elucidating systemic resistance mechanism of $B$. Laterosporus A60 and also provide a new strategy for plant disease control by PeBL2.

\section{Materials and Methods}

Medium and cultures. The Luria-Bertani (LB) medium was used for bacterial B. laterosporus strain A60 and was cultured in $200 \mathrm{ml} \mathrm{LB}$ medium at $30^{\circ} \mathrm{C}$ and $180 \mathrm{rpm}$ for 48 $\mathrm{h}$ for protein isolation

Isolation and detection of crude protein. Culture broth was centrifuged and the supernatant was added ammonium sulfate to $62 \%$ relative saturation $(\mathrm{w} / \mathrm{v})$. The sample was centrifuged at 12,000 $\mathrm{g}$ for $20 \mathrm{mins}$ at $4^{\circ} \mathrm{C}$ and the pellet was collected and dissolved in $100 \mathrm{ml}$ buffer $(25 \mathrm{mM}$ MES-NaOH, $\mathrm{pH}$ 6.2). It was further dialyzed using same buffer for $48 \mathrm{~h}$ for removing ammonium sulphate and harvesting the precipitate. Insoluble debris was removed by centrifuging and crude protein was finally collected by freeze-drying.

Purification of crude protein. ÄKTA Explore system (Amersham Biosciences) was used to purify the crude protein. The crude protein was loaded onto a HisTrap SPHF column ( $5 \mathrm{ml}$; GE-Healthcare). Briefly, washing of column was conducted with Buffer-A for eluting bound 
proteins and removing traces of any unbound proteins. An increasing linear gradient $\mathrm{NaCl}(0-1 \mathrm{M})$ was used to elute the target proteins. Buffer-A was used to monitor the elicitor activity against the tobacco plant leaf in each fraction after dialysis. (Wang et al., 2015) Furthermore, HPLC was conducted for purification of the crude proteins. Positive fractions were separated using a solution of n-butyl alcohol, isopropyl alcohol, water, and aqueous ammonia (60:20:20:10). The concentration of ACN (acetonitrile) was raised in the eluted solvent from 10 to $60 \%(\mathrm{v} / \mathrm{v})$ for $28 \mathrm{~min}$ by using increasing linear gradient at a flow rate of $0.2 \mathrm{ml} / \mathrm{min}$. T3 C18 (Waters Atlantis) reverse phase column was equilibrated $\left(2.1 \times 150 \mathrm{~mm}, 3.5 \mathrm{~m}, 40^{\circ} \mathrm{C}\right)$ with 2 $\mathrm{mM} \mathrm{NH}_{4} \mathrm{FA} / 0.1 \% \mathrm{FA} /$ water and $5 \% \mathrm{ACN}$ and the pooled active fraction were injected onto the column. Through the fraction collector, the sample was collected, coupled with the monitoring of absorbance was carried at $235 \mathrm{~nm}$. To determine the purity, each peak was tested against tobacco plant leaves while the fraction exhibiting elicitor activity was chromatographed.

Mass spectrometry analysis. Using the Triple TOF 5600 TOF MS Analyser (Applied Biosystems), the active segment collected after preparative HPLC was analyzed. MS scanning mode with a scan range of $250-2000(\mathrm{~m} /$ z) was used to acquire data. Samples were digested after lyophilization using $2 \mu \mathrm{l}$ of a $20 \%$ nitrile reconstitution. 1 $\mu \mathrm{l}$ aliquot of dissolved sample was added directly to the illustration point on the target. After allowing the solvent to dry naturally, $0.5 \mu \mathrm{l}$ of over-saturated CHCA Matrix Solution (solvent for $50 \%$ ACNO, $1 \%$ TFA) was added to the corresponding target and dried. Nitrogen was blown onto the target sample and then the sample was put into the instrument through the target trough; analysis was completed using a time-of-flight tandem mass spectrometer 5800 MALDI-TOF/TOF, AB SCIEX) To test analysis, the laser source was $355 \mathrm{~nm}$ wavelength of Nd: YAG Laser. The acceleration voltage was $2 \mathrm{kV}$ and positive ion mode and automatic data acquisition were used. The first-order mass spectrometry scan range was $800-4000 \mathrm{Da}$. A signalto-noise ratio greater than 50 was selected for the twostage mass spectrometry of mother ions (MS/MS) analysis. Each illustration click was based on the selection of an 8 A mother ion, a two-grade mass spectrometry (MS/MS) cumulative overlay of 2500, time, and a collision energy of $2 \mathrm{kV}$ with CID shut down. Using the NCBI taxonomy database against Brevibacillus laterosporus (40021), a combined (MS+MS/MS) enzyme search was carried out with the following parameters: Trypsin fixed modifications, carbamidomethyl (C); Dynamical modifications, oxidation
(Jackson et al., 2005). The mass values were as follows: Monoisotopic Protein Mass, unrestricted peptide; Mass Tolerance, \pm 100 ppm fragment; Mass Tolerance, $\pm 0.4 \mathrm{Da}$ peptide; Charge State, 1+ ax; Missed Cleavages, 1.

Expression in E. coli and purification of the recombinant protein. From the results of de novo sequencing and BLAST searches in the NCBI (www.ncbi.nlm.nih. giv/perotein/ERM166658.1) database, a peptide sequence was obtained. The primers (F primer, 5'-TCAACCACATCCTCCGTACAGC-3' and R primer, 5'-TGCTACGAACCAGAGAAGCCA-3') were designed for amplifying the gene. The genomic DNA was isolated using the Bacterial DNA Kit D3350-01 ( $\Omega$ MEGA Biotech). The elicitor-encoding gene was amplified using genomic DNA as a template. The purified fragment was cloned into a pMD18$\mathrm{T}$ simple vector (Takara Biotechnology, Dalian, China) and then transformed into Trans 1 T1 (Transgene Biotech, Beijing, China) for sequencing. The gene was constructed into the expression vector, pET-28-a, using the BamHI and $X h o \mathrm{I}$ restriction sites. The recombinant vector was then transformed into E. coli BL21 (DE3) for protein expression. The recombinant novel protein was induced by the addition of $0.5 \mathrm{mM}$ isopropyl $\beta$-D-1-thiogalactopyranoside (IPTG) (Sigma, USA). The cells were collected by centrifugation and then disrupted by an ultrasonic disruptor to obtain the supernant. The purification of the recombinant protein consisted of three sequential procedures: (1) affinity chromatography with a HisTrap HP affinity column (GE Healthcare), (2) ion exchange chromatography with a Resource Q column (GE Healthcare) and (3) size exclusion chromatography with a Superdex-200 column (GE Healthcare). By separating on SDS-PAGE and staining the polyacrylamide gel with Coomassie Brilliant Blue, the protein purity and molecular weight were determined. Protein molecular markers (Ferments, Hanover, USA) were used to estimate the size of the purified protein.

Detection of reactive oxygen species (ROS). The ROS level in the tobacco leaves was determined by the histological localization of hydrogen peroxide (Thordal-Christensen et al., 1997). In brief, 6-week-old leaves were treated with PeBL2 (5 mM or Tris (negative control)). After $24 \mathrm{~h}$ of treatment, the leaves were excised, and the sample was treated with a solution of 330 diamino-benzidine (DAB), $\mathrm{NaOH}(1 \mathrm{mg} / \mathrm{ml}$ with $\mathrm{pH}$ of 3.8). The leaves were placed in $95 \%$ ethanol after incubation at room temperature for 8 h. Further incubation was carried out at $65^{\circ} \mathrm{C}$ for $20 \mathrm{~min}$ to remove chlorophyll. The samples were observed after subsequently rinsing with 50\% ethanol (Chen et al., 2014). 
Bioassay for PeBL2-induced disease resistance. The leaves of tobacco plants were infiltrated with $50 \mu \mathrm{M}$ of PeBL2 and with BSA as control. The nontreated (systemic) leaves were inoculated with $B$. cinerea mycelial discs at 3rd day after PeBL2 treatment. $B$. cinerea infection 2 days later, the inoculated $N$. benthamiana leaves was detached and place into Petri plates with $1.5 \%$ agar medium and maintain high humidity. The diameter size was used to measure the severity of disease (Mao et al., 2010; Zhang et al., 2011).

No (Size) of lesion on control leaves

Inhibition $\%=\frac{- \text { No (Size) of lesion on protein treated leaves }}{\text { No (size) of lesions on control leaves }}$

Database Analysis. MS/MS spectra were searched against database using Mascot v2.2 (Matrix Science).

\section{Results}

Protein elicitor (PeBL2) purification. Supernatant from a culture of B. laterosporus A60 strain was used to isolate the elicitor protein. A HisTrap SP FF colum was used to purify the crude extract to produce peak a and peak b (Fig. 1A). And the two peak protein fractions were infiltrated into leaves of $N$. benthamiana to check the elicitor activity (Fig. 1B). The results demonstrated that only peak a can induce the hypersensitive response (HR) (Fig. 1B). To further purify the active fraction peak a, an Agilent HPLC by using Zorbax-Eclipse (XDB-C18) was carried out. The results showed that the initial six absorbed fractions (A, B, C, D, E, and F) were obtained (Fig. 2A). All portions were checked for elicitor activity. Only peak D have elicitor activity (Fig. 2B). Under the same conditions this peak underwent chromatography again showed a single peak as in Fig. 3A. Tricine SDS-PAGE display relative molecular mass as 17 $\mathrm{kDa}$ (Fig. 3B). Taken together, these results demonstrated that a novel protein PeBL2 was obtained.

The induction of the hypersensitive response (HR) by the protein elicitor. HR necrotic zones have been observed at infiltration sites at 24 hpi (Fig. 3C). Whereas, the corresponding protein buffer infiltrated leaves did not show any necrosis. For confirmation PeBL2 concentration for HR in detail, a series of dilutions from recombinant PeBL2 were prepared and infiltrated in tobacco leaves, the results demonstrated $50 \mu \mathrm{M}$ as the minimal elicitor protein concentration to induce HR.

Amino acid sequence. For the determination of amino

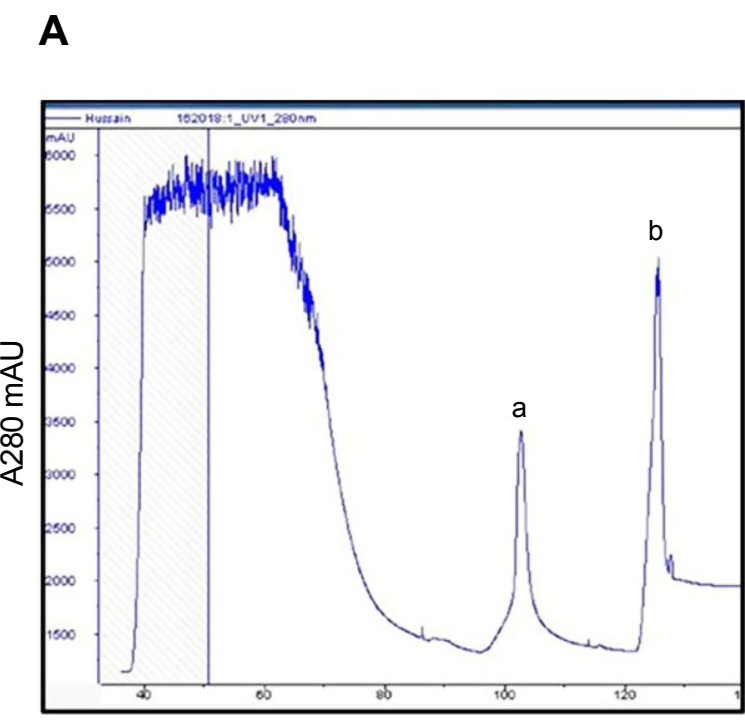

Elution Vol (mol)
B

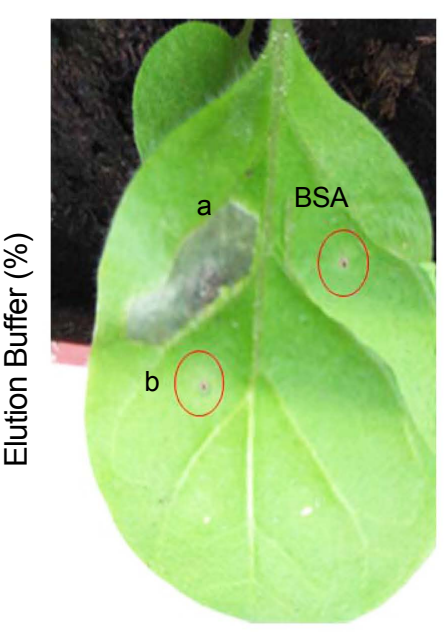

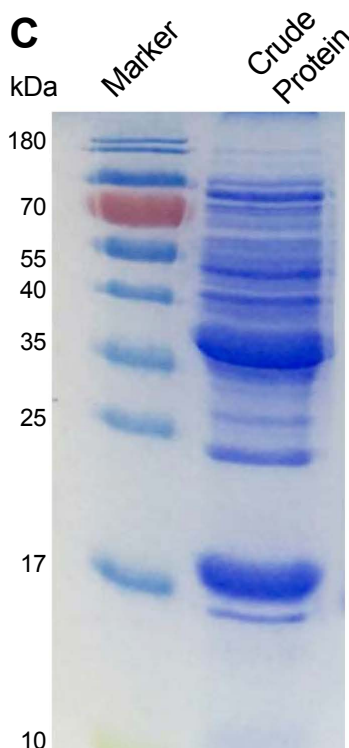

10

Fig. 1. Purification of the PeBL2 protein. (A) Cation exchange chromatography using a HisTrap SP HP column $(2.5 \mathrm{~cm} \times 20 \mathrm{~cm})$. The column was washed with buffer A (25 mM MES-NaOH, pH 6.2) to remove any unbound proteins, and the bound proteins were eluted with a linear gradient of increasing $\mathrm{NaCl}(0-1 \mathrm{M})$. Buffer B (25 mM Tris, $200 \mathrm{mM} \mathrm{NaCl}, 500 \mathrm{mM}$ imidazole, pH 8.0) was used to B. Two fractions (peak a and peak b) were produced. (B) Fractions (peak a and peak b) along with BSA (control) included in the test for HR. Out of these fractions peak a showing HR in tobacco leaves. (C) SDS-PAGE of crude proteins. 
A

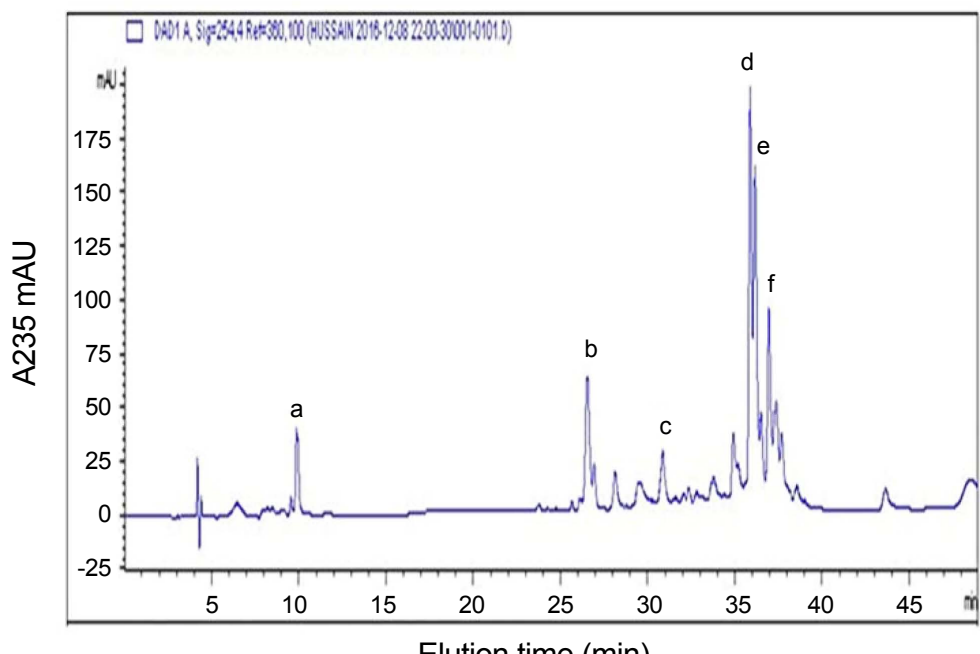

B

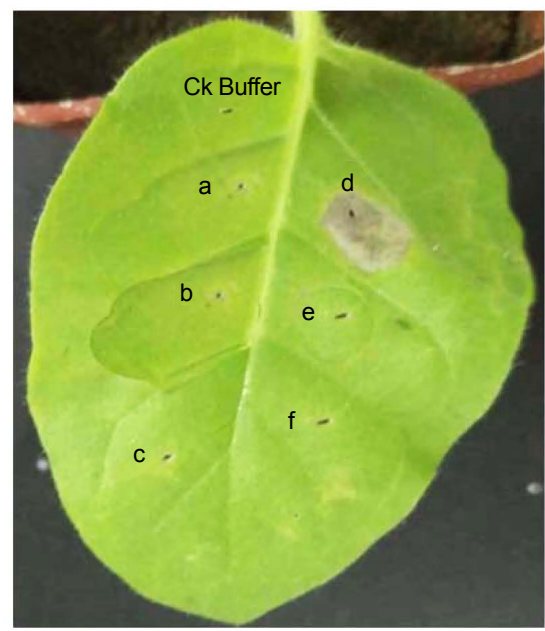

Fig. 2. Purification of the active fraction. (A) Waters Atlantis T3 C18 reversed-phase column $\left(2.1 \mathrm{~mm} \times 150 \mathrm{~mm}, 3.5 \mathrm{~m}, 40^{\circ} \mathrm{C}\right)$ was equilibrated with $5 \% \mathrm{CAN}$ and acetonitrile/2 mM NH4FA/0.1\% FA/water. The concentration of ACN in the eluted solvent was raised from $10 \%(\mathrm{v} / \mathrm{v})$ to $60 \%(\mathrm{v} / \mathrm{v})$ over $28 \mathrm{~min}$ using a linear gradient at a flow rate of $0.2 \mathrm{ml} / \mathrm{min}$. The peaks a, b, c, d, e and f were produced by HPLC. (B) All peaks were checked for HR in tobacco leaves. Out of all peaks peak d displayed an obvious HR.

\section{A}

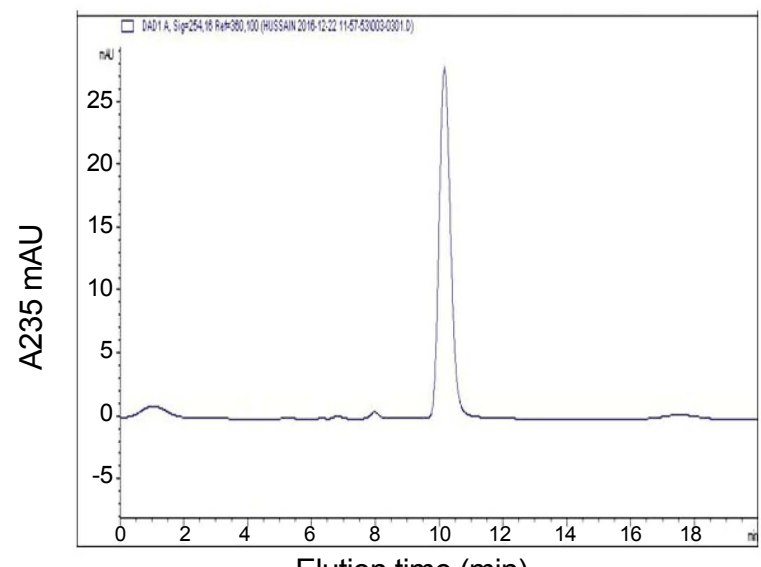

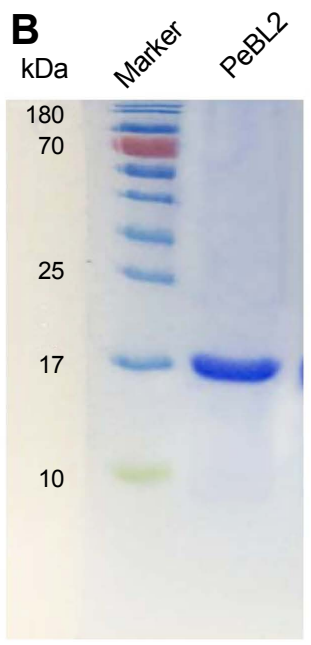

C

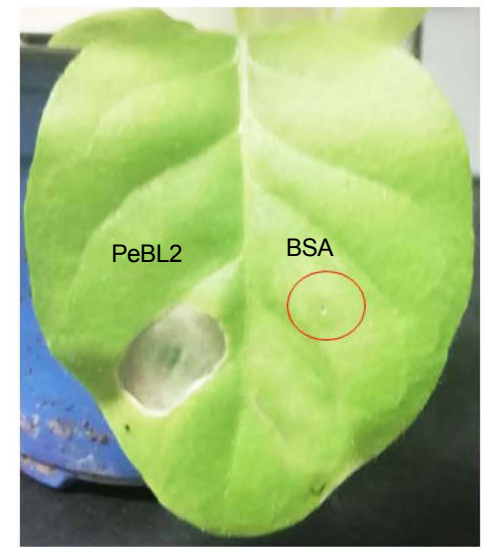

Fig. 3. Further purification of the active protein with HPLC (A) HPLC was used to further purify fraction D using Zorbax-Eclipse (XDB-C18). (B) After purification, fraction D was checked by Tricine SDS-PAGE to determine the size of the protein, which is shown as about $17 \mathrm{kDa}$. (C) The HR activation of purified single protein was checked as compared to BSA.

acid sequence HPLC was performed for in gel proteins of PeBL2. ESI-MS/MS was carried out and further analysis was performed by de-novo-quenching. A hypothetical conserved protein from the B. laterosporus (GenBank accession no. ERM16658.1), with the proteins sharing 100\% identity in the region that the sequence covered. This sequence was used to design PCR primers for cloning gene encoding PeBL2.
Phylogenetic Analysis. Phylogeny is a diagram that depicts the lines of evolutionary decent of deferent species, organisms or genes from a common ancestor. A phylogeny analysis was conducted to observe the evolutionary and functional relationship of PeBL2 members in B. laterosporus (Anbu, 2016; Wang et al., 2015; Zhao et al., 2012). All downloaded proteins sequences were aligned using MEGA6. From the resultant multiple sequence alignment, 


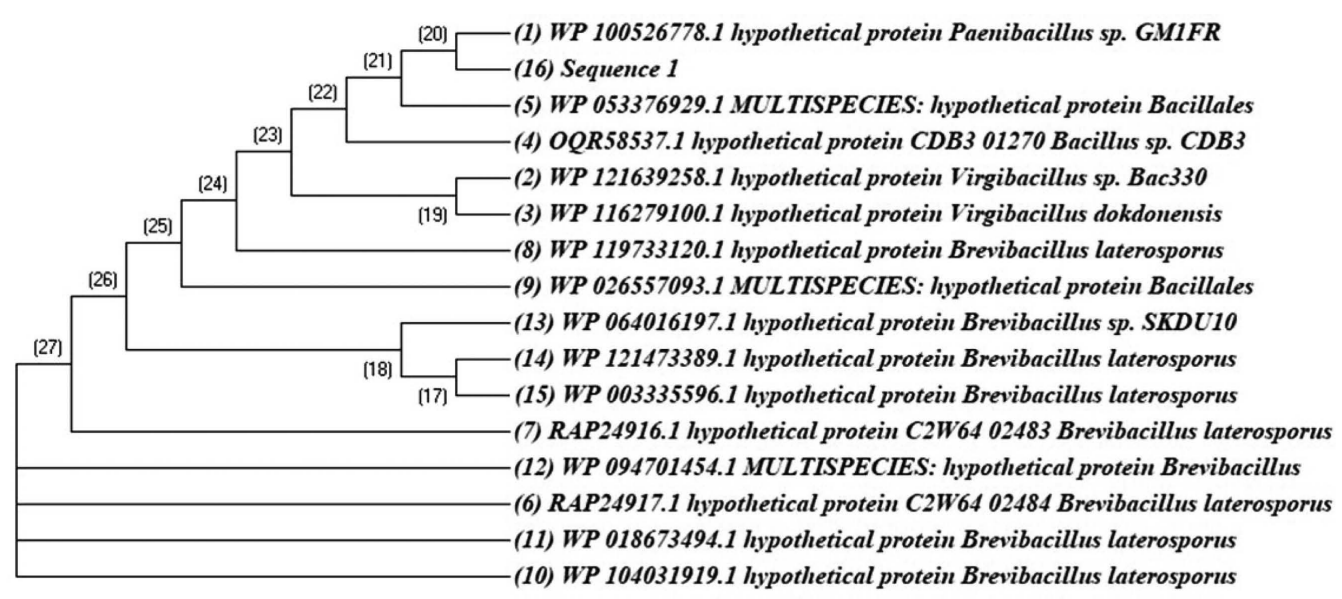

Fig. 4. Phylogenetic tree based on $16 \mathrm{~S}$ rRNA sequencing, which was generated using the neighbour-joining method. Relationships of. ERM16658.1. sequence (highlighted in yellow) to other Brevibacillus species are shown. Bar, 1 change per nucleotide position. a phylogenetic tree was constructed using the neighbourjoining method (Saitou and Nei, 1987) by a line in module in MEGA6. The reliability for internal branches was assessed using the bootstrapping method (1,000 bootstrap replicates). The final tree revealed the distribution of PeBL2 in five different groups that are also describe in (Fig. 4).
peBL2 gene sequence and heterologous expression. The full-length DNA sequence encoding PeBL2 (GenBank accession no. ERM16658.1) was amplified from the $B$. laterosporus A60 strain. The length of the PeBL2 gene is 471 $\mathrm{bp}$, encoding a protein with 156 amino acids comprising of theoretical molecular weight as $17.22 \mathrm{kDa}$. Using online software SignalP 3.0 (http://www.cbs.dtu.dk/services/SignalP-3.0/) it was confirmed that the PeBL2 is a hypotheti-
A

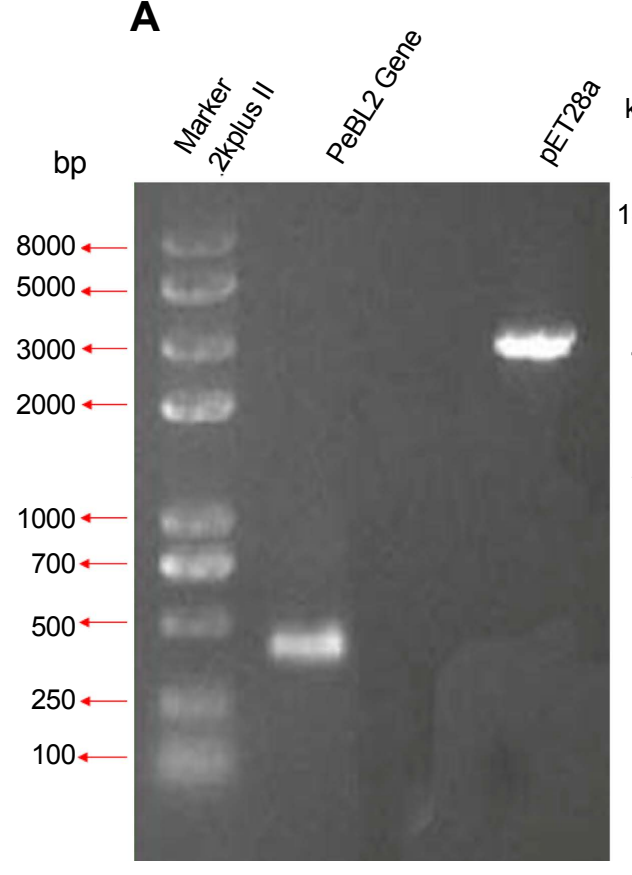

B
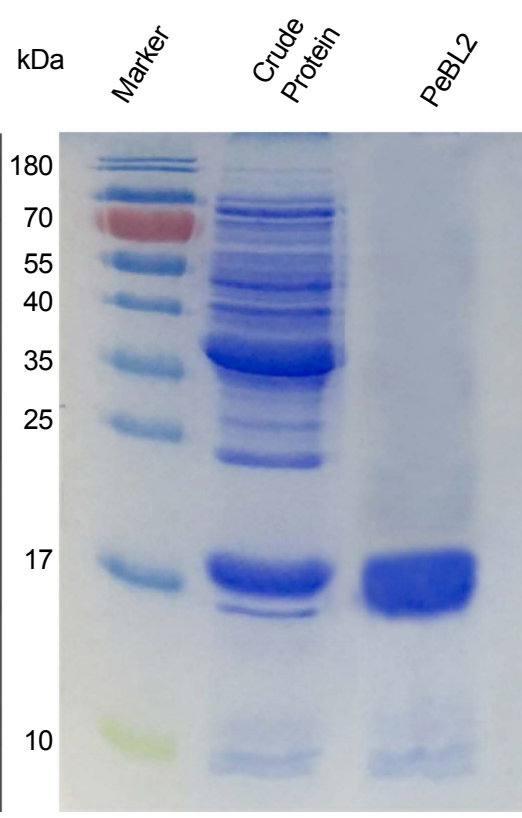

C

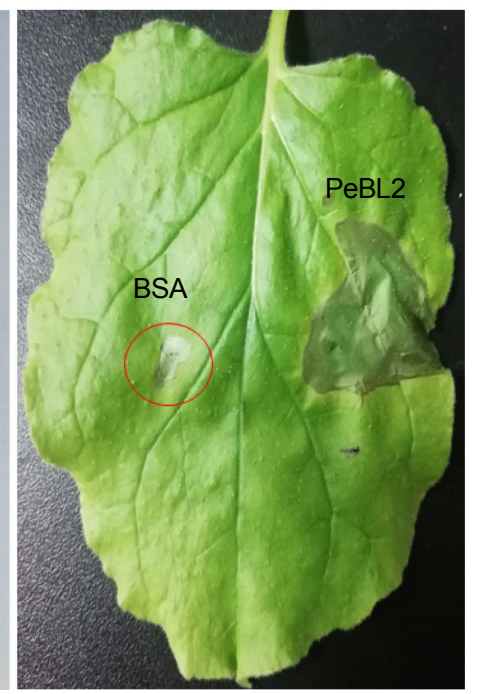

Fig. 5. Expression and purification of protein PeBL2 in E. coli. (A) PCR was used to amplify the full-length DNA sequence encoding PeBL2 from the B. laterosporus A60 strain. The length of the PeBL2 gene is $471 \mathrm{bp}$, which encodes a protein of 156 amino acids with a theoretical molecular weight of $17 \mathrm{kDa}$. The PeBL2 gene was cloned and then ligated into pET28a. (B) The recombinant protein PeBL2 was expressed and purified. SDS-PAGE of the purified elicitor protein, PeBL2, displaying a single band by Coomassie Brilliant Blue R-250 staining. (C) The hypersensitive response induced by the recombinant elicitor protein, PeBL2. The response was observed at $24 \mathrm{~h}$ post-infiltration. The elicitor treatment $(50 \mu \mathrm{m})$ and control treatment with BSA are shown. 


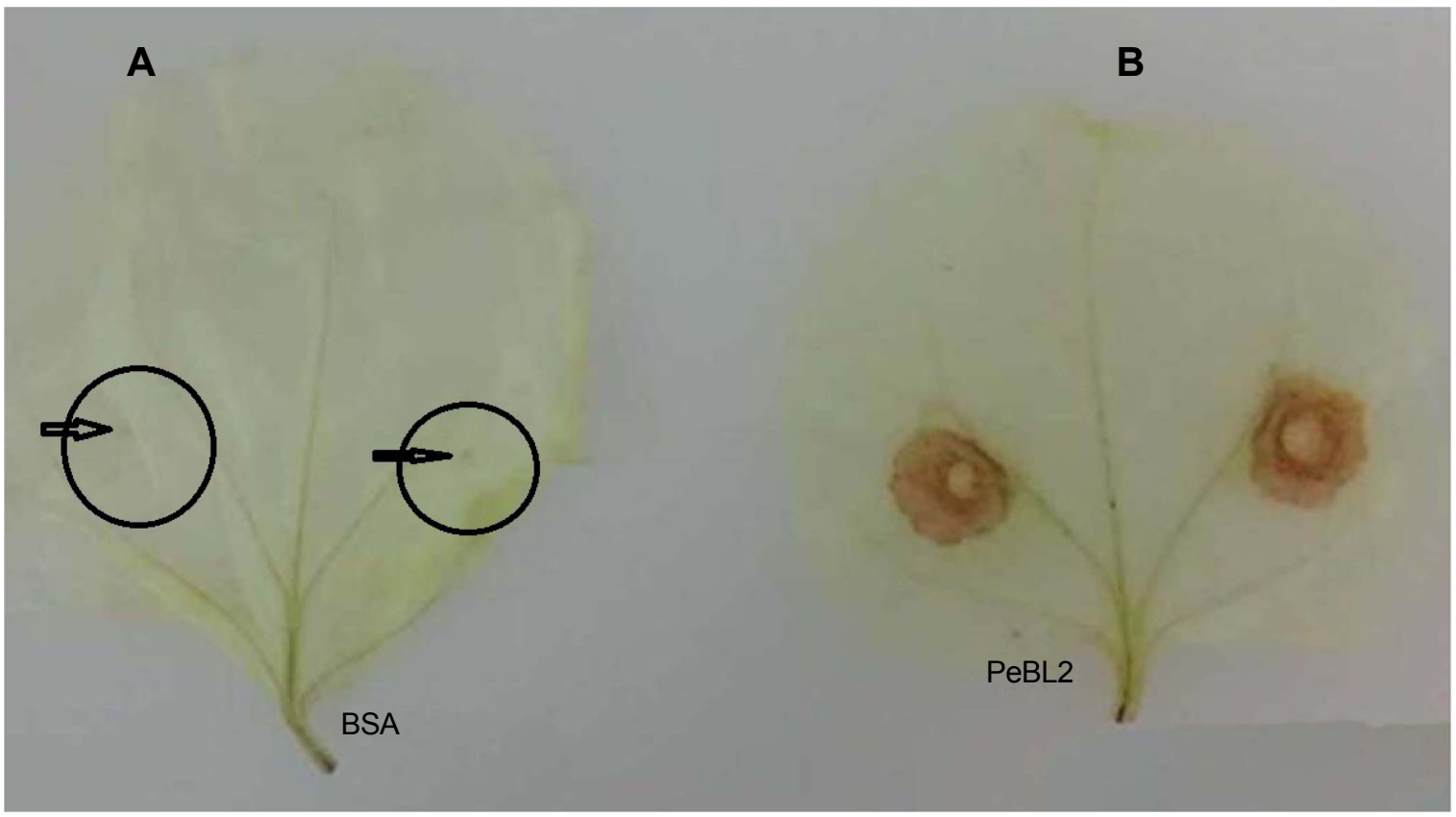

Fig. 6. ROS burst in tobacco cells after PeBL2 treatment. The brown DAB-stained precipitates represent ROS burst. (A) No ROS generate in tobacco leaves treated with BSA (control). (B) Significant ROS were observed in the recombinant PeBL2-treated areas.

cal protein. The recombinant protein expressed by pET28 $(\mathrm{a}+)$ was purified by a HisTrap-HP affinity column, Superdex-200 column and a Resource Q column. A single band with $17 \mathrm{kDa}$ molecular mass was showed on SDS-Page (Fig. 5A-C).

\section{B1}

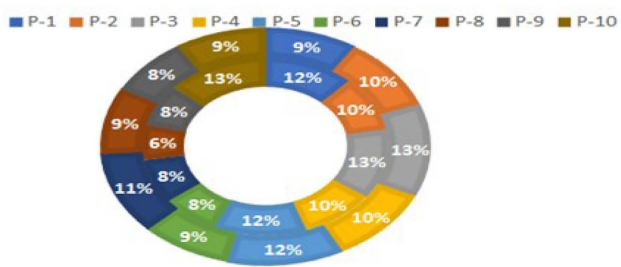

B2

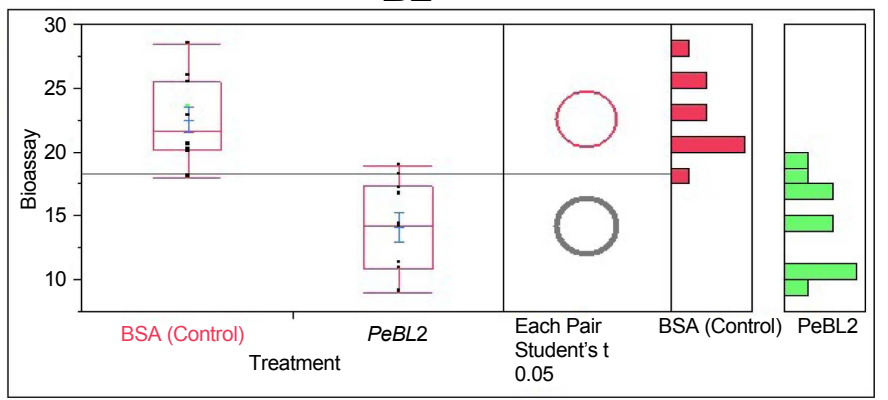

Fig. 7. Induced disease resistance against Botrytis cinerea in tobacco. (A) Representative phenotypes of disease caused by B. cinerea in PeBL2 and BSA-infiltrated tobacco leaves. The sizes of the lesions caused by $B$. cinerea in PeBL2-treated leaves were smaller than that in BSA at $36 \mathrm{~h}$ post-infiltration. (B) Lesion sizes caused by B. cinerea were measured in leaves with PeBL2 or BSA-treated plants. Data presented in (B) were calculated as follows: Inhibition $\%=[$ (No (size) of lesions on control leaves - No (size) of lesions on proteintreated leaves)/No (size) of lesions on control leaves] $\times 100 \%$. (B1) data of treated and untreated plants were plotted showing inhibition percentage rate. (B2) Statistical analysis was performed using Student's t-test (Circles), Box Plots for BSA (control) and PEBL2 (treated) representing differences among both treatments indicate significant differences between PeBL2 and BSA treatment. 
PeBL2 caused ROS accumulation. In order to examine recombinant PeBL2-activated HR biochemical responses, the accumulation of ROS generated by the plasma membrane-localized NADPH oxidase complex was analyzed (Bóka and Orbán, 2007; Rahantaniaina et al., 2017) and levels of $\mathrm{H}_{2} \mathrm{O}_{2}$ and superoxide anion $\left(\mathrm{O}_{2}^{-}\right)$production were assayed using DAB. Significant brown DAB-stained precipitates were easily observed in the recombinant PeBL2treated areas (Fig. 7A and B).

PeBL2 induced plant Systemic resistance. A $20 \mu \mathrm{M}$ recombinant PeBL2 was used for the treatment of six-weekold $N$. benthamiana leaves along with buffer (control). A mechanical inoculation of successive leaves after three days with $B$. cinerea. A supervised controlled regime of $25^{\circ} \mathrm{C}$ under a $12 \mathrm{~h}$ light/dark was maintained for these inoculated plants for daily disease symptoms observations. The disease severity as recorded through measuring lesion diameters $B$. cinerea lesions at 3 days post-inoculation 10 random injuries were measured and shown in Fig. 6A. Inhibition rate presented in Fig. 6B1 shown clear differences between treated and BSA (untreated). Fig. 6B which shows significant differences for PeBL2 and BSA treatment.

\section{Discussion}

B. laterosporus is gram positive bacteria, which produces protentional protein elicitor but not reported as biological hazard. Moreover, B. laterosporus has also been reported as capable of decomposing characteristics in organisms. Here we have determined that $B$. laterosporus A60 produce elicitor protein PeBL2 that can induce plant systemic disease resistance in tobacco plant. Elicitor has some special criteria, as well as advantages, that make it a strong candidate as a biological control agent (BCA) (Huang et al., 2005; de Oliveira et al., 2004; Saikia et al., 2011; Song et al., 2011). Furthermore, B. laterosporus can produce different types of compounds, including siderophores and antibiotics (e.g., bacilysin, iturin, mycosubtilin) that are the main reasons for its antagonistic effect. Second, it can quickly establish and demonstrate defence responses in host plants (Tian et al., 2006). And third, B. laterosporus can survive in various environmental stresses, such as UV light and desiccation, which allow for its natural formulation to be used for commercial purposes (Marche et al., 2016), and this is a fundamental principle of biological control agents (Tian et al., 2006). Regarding this aspect, the goal of this research is investigation of elicitor isolation and the exploitation of PeBL2 against devastating fungi. It is fascinating that this bacterium can harvest a short linear peptide sequence (BLAST search of the NCBI database; Accession ERM16658.1). In the PeBL2 protein, 156 amino acids were similar to another sequence (Accession ERM16658.1) The protein only showed minimal similarity to 5 other proteins isolated from different organisms, such as frogs and insects (Accession ERM16658.1). Our findings, including this sequence, specifies that PeBL2 is a novel protein elicitor. When disease resistance is induced by proteins, it is also assumed that the growth of the plant will be improved. For this reason, protein elicitor is considered as a plant health regulator and plant immunity activator (Qiu et al., 2009; Zhang et al., 2010). After inoculation of protein PeBL2, a hypersensitive response (HR) was induced in tobacco leave. It is first reported that PeBL2 has the ability to induce HR related transcription of defense genes along with necrosis features of ISR, production of ROS. The initial action in the defence of the plant was the response that led to the resistance of the plant's later invaders. Many studies suggest that various signaling molecules can be activated by bacterial protein therapy or pathogenic fungal infections. In the case of downstream cellular signaling processes, the production of reactive oxygen species $\left(\mathrm{O}_{2}^{-}\right.$and $\left.\mathrm{H}_{2} \mathrm{O}_{2}\right)$ is an active process and the earliest event during HR (Wang et al., 2016). Central generation of ROS is resulted from the production of the ROS burst enabling plants the detection of attacking pathogens as well as pathogen-derived elicitors called PAMPs (Torres, 2010). Host cell wall strengthening by glycoprotein cross linking resulted in response from stimulation of ROS production. In addition, ROS production interrelates to various molecules viz. WIPK (wound-induced protein kinase), $\mathrm{Ca}^{2+}, \mathrm{NO}$, lipids, whereas mitogen activated protein kinase (MAPK), by acting as an intracellular and/or intercellular signaling molecule which may also function in defense signaling pathways (Garciabrugger et al., 2006; Srivastava et al., 2009). The redox environment also results in ROS metabolism in the plant, which helps to regulate the function of NPR1. In the case of plant diseases, NPR1 acts as a crucial mediator of systemic responses.

\section{Conclusions}

B. laterosporus strain A60 is a novel strain which can secrete the protein elicitor PeBL2. In current study, we first report the methods for the purification, gene cloning and characterization of the newly reported protein elicitor PeBL2. We found that PeBL2 plays an important role in the induction defence-related early events, as well as HR. The induction of this elicitor in $N$. benthamiana clearly indicate its strong ability as a plant defence activator against 
pathogens. Considering the damaging effect of chemical pesticides in crop fields and human health, we can strongly suggest that PeBL2 could be very effectively used in biopesticides. Our research not only interprets the molecular mechanism of PeBL2 but also suggests the potential application of the PeBL2 from B. laterosporus strain A60 as a commercial biocontrol agent to ensure sustainable agriculture as well as product security.

\section{Acknowledgments}

This research was supported by the National Key Research and Development Program of China (2017YFD0201100).

\section{References}

Akköprü, A. and Demir, S. 2005. Biological control of fusarium wilt in tomato caused by Fusarium oxysporum f. sp. lycopersici by AMF Glomus intraradices and some rhizobacteria. J. Phytopathol. 153:544-550.

Allen, R. L., Bittner-Eddy, P. D., Grenville-Briggs, L. J., Meitz, J. C., Rehmany, A. P., Rose, L. E. and Beynon, J. L. 2004. Hostparasite coevolutionary conflict between Arabidopsis and downy mildew. Science 306:1957-1960.

Anbu, P. 2016. Enhanced production and organic solvent stability of a protease from Brevibacillus laterosporus strain PAP04. Braz. J. Med. Biol. Res. 49:e5178.

Asai, S., Ohta, K. and Yoshioka, H. 2008. MAPK signaling regulates nitric oxide and NADPH oxidase-dependent oxidative bursts in Nicotiana benthamiana. Plant Cell 20:1390-1406.

Blumwald, E., Aharon, G. S. and Lam, B. C. 1998. Early signal transduction pathways in plant-pathogen interactions. Trends Plant Sci. 3:342-346.

Bóka, K. and Orbán, N. 2007. New aspect of $\mathrm{H}_{2} \mathrm{O}_{2}$ signaling. Plant Signal. Behav. 2:498-500.

Cct, R., Vermeulen, J. P., Vels, A., Himmelbach, A., Mascher, M. and Niks, R. E. 2018. Mapping resistance to powdery mildew in barley reveals a large-effect nonhost resistance QTL. Theor. Appl. Genet. 131:1031-1045.

Chandel, S., Allan, E. J. and Woodward, S. 2010. Biological Control of Fusarium oxysporum f.sp. lycopersici on Tomato by Brevibacillus brevis. J. Phytopathol. 158:470-478.

Chen, M., Zhang, C., Zi, Q., Qiu, D., Liu, W. and Zeng, H. 2014. A novel elicitor identified from Magnaporthe oryzae triggers defense responses in tobacco and rice. Plant Cell Rep. 33:1865-1879.

Cui, A. L., Hu, X. X., Gao, Y., Jin, J., Yi, H., Wang, X. K., Nie, T. Y., Chen, Y., He, Q. Y., Guo, H. F., Jiang, J. D., You, X. F. and Li, Z. R. 2018. Synthesis and bioactivity investigation of the individual components of cyclic lipopeptide antibiotics. $J$. Med. Chem. 61:1845-1857.

de Oliveira, E. J., Rabinovitch, L., Monnerat, R. G., Passos,
L. K. and Zahner, V. 2004. Molecular characterization of Brevibacillus laterosporus and its potential use in biological control. Appl. Environ. Microbiol. 70:6657-6664.

Díez-Navajas, A. M., Wiedemann-Merdinoglu, S., Greif, C. and Merdinoglu, D. 2008. Nonhost versus host resistance to the grapevine downy mildew, Plasmopara viticola, studied at the tissue level. Phytopathology 98:776-780.

Ellis, J. G., Rafiqi, M., Gan, P., Chakrabarti, A. and Dodds, P. N. 2009. Recent progress in discovery and functional analysis of effector proteins of fungal and oomycete plant pathogens. Curr. Opin. Plant Biol. 12:399-405.

Garcia-Brugger, A., Lamotte, O., Vandelle, E., Bourque, S., Lecourieux, D., Poinssot, B., Wendehenne, D. and Pugin, A. 2006. Early signaling events induced by elicitors of plant defenses. Mol. Plant-Microbe Interact. 19:711-724.

Glazebrook, J. 2001. Genes controlling expression of defense responses in Arabidopsis. Curr. Opin. Plant Biol. 4:301-308.

Haas, D. and Défago, G. 2005. Biological control of soil-borne pathogens by fluorescent pseudomonads. Nat. Rev. Microbiol. 3:307-319.

Hazotte, A., Péron, O., Gaudin, P., Abdelouas, A. and Lebeau, T. 2018. Effect of Pseudomonas fluorescens and pyoverdine on the phytoextraction of cesium by red clover in soil pots and hydroponics. Environ. Sci. Pollut. Res. 25:20680-20690.

Hu, Y., Li, Y., Hou, F., Wan, D., Cheng, Y., Han, Y., Gao, Y., Liu, J., Guo, Y., Xiao, S., Wang, Y. and Wen, Y. Q. 2018. Ectopic expression of Arabidopsis broad-spectrum resistance gene RPW8.2 improves the resistance to powdery mildew in grapevine (Vitis vinifera). Plant Sci. 267:20-31.

Huang, C. J., Tsay, J. F., Chang, S. Y., Yang, H. P., Wu, W. S. and Chen, C. Y. 2012. Dimethyl disulfide is an induced systemic resistance elicitor produced by Bacillus cereus C1L. Pest Manag. Sci. 68:1306-1310.

Huang, X., Tian, B., Niu, Q., Yang, J., Zhang, L. and Zhang, K. 2005. An extracellular protease from Brevibacillus laterosporus G4 without parasporal crystals can serve as a pathogenic factor in infection of nematodes. Res. Microbiol. 156:719-727.

Islam, W., Noman, A., Qasim, M. and Wang, L. 2018. Plant responses to pathogen attack: Small RNAs in focus. Int. J. Mol. Sci. 19:E515.

Jackson, S. N., Wang, H. Y., and Woods, A. S. 2005. Direct profiling of lipid distribution in brain tissue using MALDITOFMS. Anal. Chem. 77:4523-4527.

Jain, S., Vaishnav, A., Kasotia, A., Kumari, S., Gaur, R. K. and Choudhary, D. K. 2013. Bacteria-induced systemic resistance and growth promotion in Glycine max L. Merrill upon challenge inoculation with Fusarium oxysporum. Proc. Natl. Acad. Sci. India 83:561-567.

Jones, J. D. G. and Dangl, J. L. 2006. The plant immune system. Nature 444:323-329.

Kloeppe, J. W., Rodríguez-Kábana, R., Zehnder, A. W., Murphy, J. F., Sikora, E. and Fernández, C. 1999. Plant root-bacterial interactions in biological control of soilborne diseases and 
potential extension to systemic and foliar diseases. Aust. Plant Pathol. 28:21-26.

Kukawka, R., Czerwoniec, P., Lewandowski, P., Pospieszny, H. and Smiglak, M. 2018. New ionic liquids based on systemic acquired resistance inducers combined with the phytotoxicity reducing cholinium cation. New J. Chem. 42:11984-11990.

Kulye, M., Liu, H., Zhang, Y., Zeng, H., Yang, X. and Qiu, D. 2012. Hrip1, a novel protein elicitor from necrotrophic fungus, Alternaria tenuissima, elicits cell death, expression of defence-related genes and systemic acquired resistance in tobacco. Plant Cell Environ. 35:2104-2120.

Lai, Y. S., Renna, L., Yarema, J., Ruberti, C., He, S. Y. and Brandizzi, F. 2018. Salicylic acid-independent role of NPR1 is required for protection from proteotoxic stress in the plant endoplasmic reticulum. Proc. Natl. Acad. Sci. U.S.A. 115:E5203-E5212.

Ma, L., Zhang, H. Y., Zhou, X. K., Yang, C. G., Zheng, S. C., Duo, J. L. and Mo, M. H. 2018. Biological control tobacco bacterial wilt and black shank and root colonization by bio-organic fertilizer containing bacterium Pseudomonas aeruginosa NXHG29. Appl. Soil Ecol. 129:136-144.

Mao, J., Liu, Q., Yang, X., Long, C., Zhao, M., Zeng, H., Liu, H., Yuan, J. and Qiu, D. 2010. Purification and expression of a protein elicitor from Alternaria tenuissima and elicitormediated defence responses in tobacco. Ann. Appl. Biol. 156:411-420.

Marche, M. G., Mura, M. E. and Ruiu, L. 2016. Brevibacillus laterosporus inside the insect body: Beneficial resident or pathogenic outsider?. J. Invertebr. Pathol. 137:58-61.

Nürnberger, T. 1999. Signal perception in plant pathogen defense. Cell. Mol. Life Sci. 55:167-182.

Ongena, M., Jourdan, E., Adam, A., Paquot, M., Brans, A., Joris, B., Arpigny, J. L. and Thonart, P. 2007. Surfactin and fengycin lipopeptides of Bacillus subtilis as elicitors of induced systemic resistance in plants. Environ. Microbiol. 9:1084-1090.

Pieterse, C. M. J. and van Loon, L. C. 1999. Salicylic acidindependent plant defence pathways. Trends Plant Sci. 4:5258.

Pieterse, C, M. J., Leon-Reyes, A., Van der Ent, S. and Van Wees, S. C. M. 2009. Networking by small-molecule hormones in plant immunity. Nat. Chem. Biol. 5:308-316.

Qiu, D., Mao, J., Yang, X. and Zeng, H. 2009. Expression of an elicitor-encoding gene from Magnaporthe grisea enhances resistance against blast disease in transgenic rice. Plant Cell Rep. 28:925-933.

Rahantaniaina, M. S., Li, S., Chatel-Innocenti, G., Tuzet, A., Mhamdi, A., Vanacker, H. and Noctor, G. 2017. Glutathione oxidation in response to intracellular $\mathrm{H}_{2} \mathrm{O}_{2}$ : key but overlapping roles for dehydroascorbate reductases. Plant Signal. Behav. 12:e1356531.

Riera, N., Wang, H., Li, Y., Li, J., Pelz-Stelinski, K. and Wang, N. 2018. Induced systemic resistance against citrus canker disease by rhizospheric bacteria. Phytopathology 108:1038-
1045.

Ryu, C. M., Pare, F. P. W. and Kloepper, J. W. 2005. Invisible signals from the underground: Bacterial volatiles elicit plant growth promotion and induce systemic resistance. Plant Pathol. J. 21:7-12.

Saikia, R., Gogoi, D. K., Mazumder, S., Yadav, A., Sarma, R. K., Bora, T. C. and Gogoi, B. K. 2011. Brevibacillus laterosporus strain BPM3, a potential biocontrol agent isolated from a natural hot water spring of Assam, India. Microbiol. Res. 166:216-225.

Saitou, N. and Nei, M. 1987. The neighbor-joining method: a new method for reconstructing phylogenetic trees. Mol. Biol. Evol. 4:406-425.

Shilina, J. V., Gushcha, M. I., Molozhava, O. S., Litvinov, S. V., and Dmitriev, A. P. 2018. Erratum to: "Induction of Arabidopsis thaliana resistance to pathogenic bacteria by lipopolysaccharide and salicylic acid”. Cytol. Genet. 52:322.

Smolińska, U. and Kowalska, B. 2018. Biological control of the soil-borne fungal pathogen Sclerotinia sclerotiorum - a review. J. Plant Pathol. 100:1-12.

Song, Z., Liu, K., Lu, C., Yu, J., Ju, R. and Liu, X. 2011. Isolation and characterization of a potential biocontrol Brevibacillus laterosporus. Afr. J. Microbiol. Res. 5:2675-2681.

Somasundaram, V., Basudhar, D., Bharadwaj, G., No, J. H., Ridnour, L. A., Cheng, R., Fujita, M., Thomas, D. D., Anderson, S. K., and McVicar, D. W. and Wink, D. A. 2018. Molecular mechanisms of nitric oxide in cancer progression, signal transduction and metabolism. Antioxid. Redox Signal. 30:1124-1143.

Srivastava, N., Gonugunta, V. K., Puli, M. R. and Raghavendra, A. S. 2009. Nitric oxide production occurs downstream of reactive oxygen species in guard cells during stomatal closure induced by chitosan in abaxial epidermis of Pisum sativum. Planta 229:757-765.

Thordal-Christensen, H., Zhang, Z., Wei, Y. and Collinge, D. B. 1997. Subcellular localization of $\mathrm{H}_{2} \mathrm{O}_{2}$ in plants. $\mathrm{H}_{2} \mathrm{O}_{2}$ accumulation in papillae and hypersensitive response during the barley-powdery mildew interaction. Plant J. 11:11871194.

Tian, B., Li, N., Lian, L., Liu, J., Yang, J. and Zhang, K. Q. 2006. Cloning, expression and deletion of the cuticle-degrading protease BLG4 from nematophagous bacterium Brevibacillus laterosporus G4. Arch. Microbiol. 186:297-305.

Torres, M. A. 2010. ROS in biotic interactions. Physiol. Plant. 138:414-429.

Ueki, A., Kaku, N. and Ueki, K. 2018. Role of anaerobic bacteria in biological soil disinfestation for elimination of soil-borne plant pathogens in agriculture. Appl. Microbiol. Biotechnol. 102:6309-6318.

van Loon, L. C., Bakker, P. A. and Pieterse, C. M. 1998. Systemic resistance induced by rhizosphere bacteria. Annu. Rev. Phytopathol. 36:453-483.

Wang, H., Yang, X., Guo, L., Zeng, H. and Qiu, D. 2015. PeBL1, a novel protein elicitor from Brevibacillus laterosporus strain 
A60, activates defense responses and systemic resistance in Nicotiana benthamiana. Appl. Environ. Microbiol. 81:27062716.

Wang, N., Liu, M., Guo, L., Yang, X. and Qiu, D. 2016. A novel protein elicitor (PeBA1) from Bacillus amyloliquefaciens NC6 induces systemic resistance in Tobacco. Int. J. Biol. Sci. 12:757-767.

Wei, C., Zhu, L., Wen, J., Yi, B., Ma, C., Tu, J., Shen, J. and Fu, T. 2018. Morphological, transcriptomics and biochemical characterization of new dwarf mutant of Brassica napus. Plant Sci. 270:97-113.

Wei, Z. M., Laby, R. J., Zumoff, C. H., Bauer, D. W., He, S. Y., Collmer, A. and Beer, S. V. 1992. Harpin, elicitor of the hypersensitive response produced by the plant pathogen Erwinia amylovora. Science 257:85-88.

Wu, G., Liu, Y., Xu, Y., Zhang, G., Shen, Q. R. and Zhang, R. 2018. Exploring elicitors of the beneficial rhizobacterium Bacillus amyloliquefaciens SQR9 to induce plant systemic resistance and their interactions with plant signaling pathways. Mol. Plant-Microbe Interact. 31:560-567.

Zhang, H., Yu, P., Zhao, J., Jiang, H., Wang, H., Zhu, Y., Botella, M. A., Šamaj, J., Li, C. and Lin, J. 2018b. Expression of tomato prosystemin gene in Arabidopsis reveals systemic translocation of its mRNA and confers necrotrophic fungal resistance. New Phytol. 217:799-812.

Zhang, W., Yang, X., Qiu, D., Guo, L., Zeng, H., Mao, J. and Gao, Q. 2011. PeaT1-induced systemic acquired resistance in tobacco follows salicylic acid-dependent pathway. Mol. Biol. Rep. 38:2549-2556.

Zhang, Y., Yan, X., Guo, H., Zhao, F. and Huang, L. 2018a. A novel protein elicitor BAR11 from Saccharothrix yanglingensis Hhs.015 improves plant resistance to pathogens and interacts with catalases as targets. Front. Microbiol. 9:700.

Zhang, Y. H., Yang, X. F., Liu, Q., Qiu, D. W., Zhang, Y. L., Zeng, H. M., Yuan, J. J. and Mao, J. J. 2010. Purification of novel protein elicitor from Botrytis cinerea that induces disease resistance and drought tolerance in plants. Microbiol. Res. 165:142-151.

Zhao, J., Davis, L. C. and Verpoorte, R. 2005. Elicitor signal transduction leading to production of plant secondary metabolites. Biotechnol. Adv. 23:283-333.

Zhao, J., Guo, L., Zeng, H., Yang, X., Yuan, J., Shi, H., Xiong, Y., Chen, M., Han, L. and Qiu, D. 2012. Purification and characterization of a novel antimicrobial peptide from Brevibacillus laterosporus strain A60. Peptides 33:206-211. 